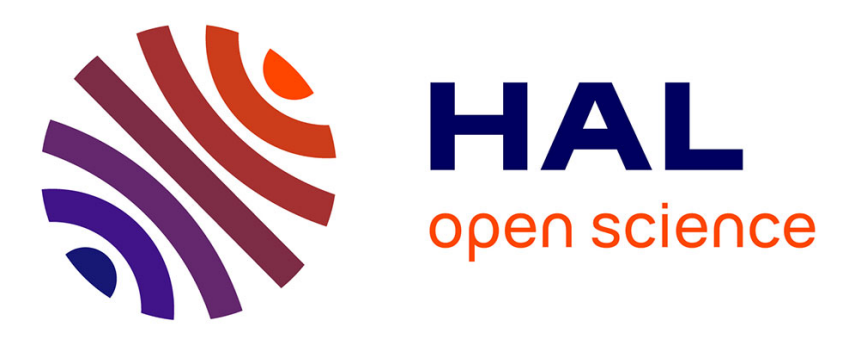

\title{
Unraveling the simultaneous shock magnetization and demagnetization of rocks
}

\author{
J. Gattacceca, M. Boustie, E. Lima, B.P. Weiss, T. de Resseguier, J.P.
}

Cuq-Lelandais

\section{- To cite this version:}

J. Gattacceca, M. Boustie, E. Lima, B.P. Weiss, T. de Resseguier, et al.. Unraveling the simultaneous shock magnetization and demagnetization of rocks. Physics of the Earth and Planetary Interiors, 2010, 182 (1-2), pp.42. 10.1016/j.pepi.2010.06.009 . hal-00675795

\section{HAL Id: hal-00675795 \\ https://hal.science/hal-00675795}

Submitted on 2 Mar 2012

HAL is a multi-disciplinary open access archive for the deposit and dissemination of scientific research documents, whether they are published or not. The documents may come from teaching and research institutions in France or abroad, or from public or private research centers.
L'archive ouverte pluridisciplinaire HAL, est destinée au dépôt et à la diffusion de documents scientifiques de niveau recherche, publiés ou non, émanant des établissements d'enseignement et de recherche français ou étrangers, des laboratoires publics ou privés. 


\section{Accepted Manuscript}

Title: Unraveling the simultaneous shock magnetization and demagnetization of rocks

Authors: J. Gattacceca, M. Boustie, E. Lima, B.P. Weiss, T. de Resseguier, J.P. Cuq-Lelandais

(1)

$=$

PII:

S0031-9201(10)00129-9

DOI:

doi:10.1016/j.pepi.2010.06.009

Reference:

PEPI 5301

To appear in: $\quad$ Physics of the Earth and Planetary Interiors

Received date: $\quad$ 5-3-2010

Revised date: $\quad 8-6-2010$

Accepted date: $\quad$ 21-6-2010

Please cite this article as: Gattacceca, J., Boustie, M., Lima, E., Weiss, B.P., de Resseguier, T., Cuq-Lelandais, J.P., Unraveling the simultaneous shock magnetization and demagnetization of rocks, Physics of the Earth and Planetary Interiors (2010), doi:10.1016/j.pepi.2010.06.009

This is a PDF file of an unedited manuscript that has been accepted for publication. As a service to our customers we are providing this early version of the manuscript. The manuscript will undergo copyediting, typesetting, and review of the resulting proof before it is published in its final form. Please note that during the production process errors may be discovered which could affect the content, and all legal disclaimers that apply to the journal pertain. 


\title{
Unraveling the simultaneous shock magnetization and demagnetization of rocks
}

\author{
Gattacceca J. ${ }^{1}$, Boustie M. ${ }^{2}$, E. Lima ${ }^{3}$, B.P. Weiss ${ }^{3}$, de Resseguier T. ${ }^{2}$, J.P. Cuq-Lelandais ${ }^{2}$ \\ 1: CEREGE (CNRS / Université Aix-Marseille), BP80, 13545 Aix-en-Provence Cedex 4, France \\ 2: LCD, UPR CNRS 9028, ENSMA, 1 avenue Clément Ader, BP 40109, 86961 Futuroscope Cedex, France \\ 3: Department of Earth, Atmospheric, and Planetary Sciences, Massachusetts Institute of Technology, \\ Cambridge, MA 02139, USA
}

\begin{abstract}
In the natural case of an hypervelocity impact on a planetary or asteroidal surface, two competing phenomena occur: partial or complete shock demagnetization of preexisting remanence and acquisition of shock remanent magnetization (SRM). In this paper, to better understand the effects of shock on the magnetic history of rocks, we simulate this natural case through laser shock experiments in controlled magnetic field. As previously shown, SRM is strictly proportional to the ambient field at the time of impact and parallel to the ambient field. Moreover, there is no directional or intensity heterogeneity of the SRM down to the scale of $\sim 0.2 \mathrm{~mm}^{3}$. We also show that the intensity of SRM is independent of the initial remanence state of the rock. Shock demagnetization and magnetization appear to be distinct phenomena that do not necessarily affect identical populations of grains. As such, shock demagnetization is not a limiting case of shock magnetization in zero field.

As a consequence, when it can be recognized in a rock, SRM must be considered as a reliable record of the direction and intensity of the ambient magnetic field at the time of impact. The natural process of hypervelocity impact where a rock carrying a remanent magnetization is shocked in the presence of an ambient field can be studied as the simple superimposition of shock demagnetization and shock magnetization. For this there are now a variety of techniques that allow experimental study of both phenomena separately or simultaneously as in this study.

These results have potential implications for the paleomagnetic study of meteorites, and lunar rocks, and for the understanding of the magnetic signature (as studied through paleomagnetism and/or magnetic anomalies) of terrestrial, lunar and Martian impact craters.
\end{abstract}

\section{Introduction}

An understanding of the effects of shock on the remanent magnetization of rocks is important for the interpretation of the magnetic anomalies of extensively cratered planetary surfaces like those on Mars (e.g., Hood et al., 2003; Shahnas and ArkaniHamed, 2007; Louzada et al., 2009), and the Moon (e.g., Halekas et al., 2003; Hood and Artemieva, 2008). It is also crucial for the understanding of the paleomagnetic signal of meteorites and lunar rocks that have all been shocked (see discussion in e.g., Carporzen et al., 2010; Yu et al., 2009, Weiss et al. 2009). To a lesser extent, the interpretation of the paleomagnetic record of terrestrial craters also requires the identification of possible shock effects on remanence (see, for instance, Louzada et al., 2008).

The first generation of studies dealing with the effect of shocks on magnetic remanence was published in the 1970's, motivated by the return of Apollo lunar 
samples (Nagata, 1971; Fuller et al., 1974; Pohl et al., 1975; Cisowski et al., 1976; Martelli and Newton, 1977; Fuller, 1977; Cisowski and Fuller, 1978). A second generation, partly triggered by the discovery of magnetic anomalies associated with the impact basins on Mars (Acuña et al., 1999), was published during the past decade (Dickinson and Wasilewski, 2000; Kletetschka et al., 2004; Louzada et al., 2007; Gattacceca et al., 2006, 2007, 2008). Most of these experimental studies dealt with shock demagnetization, i.e. the destruction of previous remanence by shock waves either in zero field (when dealing with natural remanence) or in the Earth field (equivalent to zero field when dealing with artificial isothermal saturation remanence).

Although more data are clearly needed for ferromagnetic FeNi alloys (kamacite, taenite, tetrataenite) that are the most common remanence carrier in meteorites and lunar rocks, we now have a fair understanding of shock demagnetization processes. And although definitive experimental proof is still lacking, there are indications that for pressures below the Hugoniot elastic limit (typically 1-5 GPa for silicate minerals), dynamic pressure (shock experiments) and static pressure (hydrostatic pressure experiments) give the same demagnetizing effect, so that the results of the experimental demagnetization by hydrostatic pressure (e.g. Rochette et al., 2003; Gilder et al., 2006; Bezaeva et al., 2007; Bezaeva et al., 2010) can be safely extended to the shock processes.

Shock magnetization, i.e. the acquisition of new remanence by shock in the presence of a magnetic field, has received much less attention (Nagata, 1971; Pohl et al., 1975; Pohl et al., 1981, Nagata et al., 1983; Gattacceca et al., 2008; Funaki and Syono, 2008) in part because it is experimentally more demanding as it requires ambient field control during the shock experiments. Yet, the fundamental properties of shock remanent magnetization (SRM, defined by Nagata, 1971) are now well established (Pohl et al., 1975; Gattacceca et al., 2008): SRM is proportional to the ambient field in the low-field $(<\sim 1 \mathrm{mT})$ limit and is strictly parallel to the ambient magnetic field for magnetically isotropic rocks; its intensity is independent of the angle between the shock wave propagation direction and the ambient field for isotropic rocks, it can have a significant intensity compared to thermoremanent magnetization (TRM) acquired in the same ambient field (e.g. up to $36 \%$ in Gattacecca et al., 2008); and it has a coercivity spectrum shifted towards lower values compared to that of TRM.

However, in the natural case of an hypervelocity impact on a planetary or asteroidal surfaces, two competing phenomena occur: partial or complete shock demagnetization of pre-existing remanence and acquisition of SRM. In this paper, we simulate experimentally this natural case to better understand the effects of shock on the magnetic history of rocks, and, in particular, possible interactions between these two phenomena. We also incorporate new information on the basic properties of the shock magnetization process such as small-scale $\left(\mathrm{mm}^{3}\right)$ directional homogeneity.

\section{Material and methods}

We conducted shock experiments with a pulsed laser in controlled magnetic field using the same experimental setting as in Gattacceca et al. (2008) which is briefly described by figure 1. Laser shock experiments were conducted at Laboratoire de Combustion et Détonique (LCD, Poitiers, France). The target rock was a basalt whose petrography and rock magnetic properties are described in length in Gattacceca et al. (2008). In summary, this basalt contains pseudo-single domain titanomagnetite (with $\mathrm{B}_{\mathrm{cr}} / \mathrm{B}_{\mathrm{c}}=2.29$, and $\mathrm{M}_{\mathrm{rs}} / \mathrm{M}_{\mathrm{s}}=1.82$, with respective standard deviation 0.20 and 0.16 as 
measured on 12 samples, where $B_{c r}$ is the coercivity of remanence, $B_{c}$ is the coercivity, $\mathrm{M}_{\mathrm{rs}}$ is saturation remanence, and $\mathrm{M}_{s}$ is saturation magnetization), with blocking temperatures up to $300^{\circ} \mathrm{C}$. Moreover this basalt was shown to be magnetically homogeneous at least to the scale of $10^{-2} \mathrm{~cm}^{3}$, well below the size of the samples used in this study $\left(\sim \mathrm{cm}^{3}\right)$. The mechanical properties and the behavior under shock are described in Berthe et al. (2007). In this work, shock wave propagation was modeled in a 2D axisymmetric configuration using the Radioss software and the Hyperworks suite from Altair ${ }^{\circledR}$ (Gary, 2002). As discussed in Gattacceca et al. (2008), the peak pressure reached during laser shock experiments is heterogeneous throughout the sample, as the shock wave decays rapidly away from the impact spot. Twenty samples were shocked using a laser flux of $1.8 \mathrm{GW} \cdot \mathrm{cm}^{-2}$ in water-confined regime (e.g., Fabbro et al., 1989). This flux produces pressures ranging from $2 \mathrm{GPa}$ at the impact spot, about $0.3 \mathrm{GPa}$ at the bottom of the sample, and $0.1 \mathrm{GPa}$ on the sides of the sample (figure 2), with a median value of about $0.3 \mathrm{GPa}$. ). An additional three samples were shocked with a higher flux of $4.0 \mathrm{GW} \cdot \mathrm{cm}^{-2}$.

In this study, we used the very same basalt cylindrical samples $(10 \mathrm{~mm}$ high, $9.5 \mathrm{~mm}$ in diameter, about $2.2 \mathrm{~g}$ ) that were used in Gattacceca et al. (2008). This was made possible because low-pressure laser shocks are fully nondestructive such that the same samples can be shocked repeatedly. In this former study, samples were demagnetized before the shock experiments in order to study SRM acquisition only. In the present work, samples were given a laboratory TRM (by heating up to $300^{\circ} \mathrm{C}$ in a controlled magnetic field in the 50 to $294 \mu \mathrm{T}$ range, see Table 1) using a Magnetic Measurements ${ }^{\mathrm{TM}}$ MMTD oven, and successively shocked in an ambient field perpendicular to this TRM. Subsequent alternating field (AF) demagnetization allows quantification of the shock demagnetization of the TRM (by studying the component of magnetization parallel to the original TRM) and of the acquisition of SRM (by studying the component of magnetization acquired parallel to the ambient field at the time of shock). All bulk remanence measurements were performed with a 2G Superconducting Rock Magnetometer (model 755R) at CEREGE (Aix-en-Provence, France).

In detail, samples were initially demagnetized by AF, then given an initial TRM (in an ambient field of intensity between 50 and $300 \mu \mathrm{T}$ ) that was AF demagnetized in order to obtain the coercivity spectrum of the TRM. A second TRM was then imparted using the same ambient field intensity. Although there is a risk that repeated laboratory heating result in thermal alteration of magnetic minerals, TRM was chosen as the initial remanent magnetization because it is probably the most common type of crustal magnetization on planets and asteroids, and was therefore more representative of natural processes than for instance anhysteretic remanent magnetization. In order to check that the magnetic mineralogy was not modified by the heating experiments, magnetic susceptibility was measured before and after the TRM acquisitions and those few samples that showed variation greater than $10 \%$ were discarded. Similarly, two samples that showed variation between the two TRM intensities of greater than $10 \%$ were discarded. Ultimately, 20 samples were selected for the shock experiments.

\section{Experimental results}

\subsection{Generalities}

All results are summarized in table 1 . Figure 3 shows typical demagnetization diagrams obtained during demagnetization of the samples. A first batch of 4 samples 
was shocked in zero field $(<100 \mathrm{nT})$ in order to independently study shock demagnetization of the TRM. These samples display a single component of magnetization which is a partially shock-demagnetized TRM (fig 3a). The pre-shock TRM demagnetization plot for the same sample is shown for comparison (fig $3 \mathrm{~b}$ ). The remaining 16 samples were shocked in an ambient field equal to the field that was used to impart TRM. Their AF demagnetization diagrams display two components of magnetization: the partially shock-demagnetized TRM and the newly acquired SRM (fig 3c-d).

\subsection{Shock demagnetization of TRM}

The 20 samples that were shocked with a mean laser flux of $1.85 \mathrm{GW} \cdot \mathrm{cm}^{-2}$ (s.d. $0.07 \mathrm{GW} . \mathrm{cm}^{-2}$ ) showed an average shock demagnetization of their TRM of $27 \%$ (s.d. $5 \%$ ). This value is independent of the initial TRM intensity (figure 4a). Note that the variations in initial TRM intensities among samples are linked to varying ambient magnetic field during TRM acquisition, and not to variations in their intrinsic magnetic properties. Shock demagnetization of the TRM is also independent of the strength of the magnetic field at the time of impact (figure $4 \mathrm{~b}$ ). However a possible slight tendency for increasing demagnetization with ambient field (resp. initial TRM intensity) can be observed in figure $4 \mathrm{~b}$ (resp. $4 \mathrm{a}$ ). The correlation in figure $4 \mathrm{~b}$ is more robust, especially because the four samples shocked in zero field show the lowest TRM demagnetization, which doest not fit in the trend seen in figure $4 \mathrm{a}$, which seem to discard a weak interaction between TRM and SRM. The possible relation between TRM demagnetization efficiency and the ambient field during shock cannot be attributed to the ambient field not being applied exactly perpendicular to the TRM during the shock experiment, because in that case the necessary misalignment angle can be estimated to $\sim 16^{\circ}$, which is well above the errors on the sample positioning and the ambient field direction during the experiments. This second order effect may be caused by the fact that an increasing ambient field, together with the shock wave, participate to overcome the energy limit necessary to remagnetize a given grain. This would not be in accord with Néel's (1949) theory for single domain grains, and attributable to the pseudo-single domain grain size of the magnetite in the studied basalt. This effect should also be visible for the TRM process (i.e. TRM of rocks with non single domain magnetic carriers may demagnetize easier in presence of a perpendicular magnetic field) but we are unaware of any study of this kind.

The 3 samples shocked with a higher flux $\left(4.0 \mathrm{GW} . \mathrm{cm}^{-2}\right.$, s.d. $\left.0.5 \mathrm{GW} . \mathrm{cm}^{-2}\right)$ were demagnetized by $58 \%$ (s.d. 5\%). This indicates that the TRM shock demagnetization process has not reached its limit at the relatively low pressures $(\sim 0.5 \mathrm{GPa}$ median pressure for the $1.8 \mathrm{GW} . \mathrm{cm}^{-2}$ laser flux) used in this study. For all experiments, shock demagnetization affects preferentially low coercivity grains as discussed in more details in $§ 4$.

Pressure demagnetization of TRM for the same basalt was studied in Bezaeva (2010) through hydrostratic pressure experiments with typical hold time at peak pressure of $10^{2}-10^{3} \mathrm{~s}$. The demagnetization was of about $10 \%$ for $0.2 \mathrm{GPa}, 30 \%$ for $0.5 \mathrm{GPa}$, and $45 \%$ for $1 \mathrm{GPa}$. These values are in general agreement with the $26 \%$ bulk demagnetization that was measured in this study for samples shocked with $1.8 \mathrm{GW} \cdot \mathrm{cm}^{-2}$ fluxes [most of whose volumes reached pressures in the 0.2 to $1 \mathrm{GPa}$ range (figure 2)] and typical hold time at peak pressure of 25-30 ns. 


\subsection{Shock magnetization}

In addition to our previous work (Gattacceca et al., 2008), we provide here additional information about SRM directional homogeneity. Indeed, there has been some debate about whether small-scale heterogeneities could exists, due to, for instance, to local transient magnetic fields during shock wave propagation or other hypothesized effects (Crawford and Schultz, 1988, 1999; Soloviev and Sweeney, 2005; Funaki and Syono, 2008). To study the homogeneity of SRM acquisition, an additional basalt sample was AF demagnetized and imparted with an SRM using a $1.9 \mathrm{GW} \cdot \mathrm{cm}^{-2}$ laser flux. Eleven mutually oriented $\sim 10 \mathrm{~mm}^{3}$ sub-samples were then cut with a wire saw and AF demagnetized. The SRM directions obtained for the 11 sub-samples show a remarkable clustering with a Fisher (1953) precision parameter $k=259$. The associated semi-angle of the $95 \%$ confidence cone $\left(\alpha_{95}=2.8^{\circ}\right)$ is well within the orientation uncertainties during sub-sampling and magnetic measurements, so that SRM exhibits directional homogeneity at least down to the scale of a few $\mathrm{mm}^{3}$.

Previous SRM acquisition experiments on the same basalt with the exact same shock protocol showed that the intensity of SRM was surprisingly almost homogeneous in the sample despite heterogeneous peak pressure values (Gattacceca et al., 2008). In order to verify that this property holds at the microscale and to check for possible variations in SRM intensity throughout the sample, we prepared a $500 \mu \mathrm{m}$-thick polished thin section from the central vertical section of the shocked cylinder. The sawing direction was such that the SRM was perpendicular to the slice (figure 5a). The vertical (out-of-the-plane) component of the thin section's magnetic field was then mapped using the Superconducting Quantum Interference Device (SQUID) microscope (Fong et al., 2005; Weiss et al., 2007) in the MIT Paleomagnetism Laboratory (sensor-to-sample distance of $\sim 600 \mu \mathrm{m}$ ). Figure 5b shows the measured map of the vertical component of the field, and figures $5 \mathrm{c}$ and $5 \mathrm{~d}$ show the maps of the horizontal components estimated from the measured data using the technique described in Lima and Weiss (2009).

Based on the field maps, the magnetization distribution within the sample was recovered by means of an inverse problem. We used an inversion algorithm presented in Weiss et al. (2007), incorporating the non negligible vertical sample thickness. In essence, three parallel layers of unidirectional (vertically oriented) dipolar sources were evenly distributed within the sample, and the intensity of each dipole was obtained. While this multilayer model yields better accuracy, the variations in magnetization intensity along the sample's thickness are not meaningful. Therefore, we combined all three layers for visualization purposes by adding them together. This two-dimensional magnetization distribution can be viewed as an "average" distribution, resulting from integrating along the thickness of the sample. We provide an image of the SRM distribution acquired by the basalt sample (figure 5e). SRM intensity appears homogeneous throughout the sample. For comparison and normalization purposes, we provide as well an image of the anhysteretic remanent magnetization (ARM) distribution of the same sample (figure 5f). The two images are qualitatively similar, which indicates that SRM is indeed acquired with roughly the same intensity throughout the whole sample as evidenced at the scale of a few $\mathrm{mm}^{3}$ in Gattacceca et al. (2008). This implies that the SRM intensity does not depend strongly on pressure in the 0.2 to $1 \mathrm{GPa}$ range for this particular basalt.

To further illustrate this point, Figure $5 \mathrm{~g}$ shows the average magnetization calculated along the top-bottom direction. Only sources with magnitudes greater than $10 \%$ of the 
maximum magnetization of the corresponding line were used in the averaging process, so as to minimize artifacts due to non-magnetic minerals and irregular sample shape. In addition, each curve was normalized by the corresponding overall average moment. It is clear that there is no major difference between the SRM and ARM magnetization profiles. However, the profiles suggest that the SRM may be slightly relatively concentrated in the center of the sample, which would be consistent with the location of highest pressure. As a consequence, even though the peak pressure is not homogeneous within the sample, we show here that the SRM is mostly homogeneous in intensity throughout the sample. In addition, the small residuals obtained in our inversions using a unidirectional model (root-mean-square (RMS) residuals of $\sim 5 \%$ of RMS field) indicate that the magnetization direction is also constant throughout the sample, with the possible exception of a few isolated spots located at the edges of the specimen. These artifacts-which we attribute to sample preparation-locally increased the residuals and had a negative impact on the RMS value. However, within the sample region, residuals were 4 to 5 times smaller than the RMS value, thereby showing an excellent agreement between model and data. Thus, the observed homogeneity in magnetization direction and intensity down to the microscale justifies working on the bulk samples instead of studying separate sub-samples.

As already shown in previous studies (Pohl et al., 1975; Gattacceca et al., 2008) the intensity of the SRM acquired during the shock experiments is proportional to the ambient field at the time of impact and is estimated here to be $1.51 \times 10^{-5} \mathrm{Am}^{2} /(\mathrm{kg} \cdot \mu \mathrm{T})$ (s.d. $\left.=0.29 \times 10^{-5} \mathrm{Am}^{2} /(\mathrm{kg} \cdot \mu \mathrm{T}), n=16\right)$. From the SRM intensities measured by Gattacceca et al. (2008) on previously demagnetized samples, we compute a SRM of $1.26 \times 10^{-5}$ $\mathrm{Am}^{2} /(\mathrm{kg} \cdot \mu \mathrm{T})\left(\right.$ s.d. $\left.=0.15 \times 10^{-5} \mathrm{Am}^{2} /(\mathrm{kg} \cdot \mu \mathrm{T}), \mathrm{n}=28\right)$. These two indistinguishable values show that SRM acquisition is the same whether the sample is demagnetized or carries a remanence before the shock. This is exemplified by figure 6 which displays the SRM acquired by the basalt carrying a TRM before shock (this study, SRM1 in Table 1) and the SRM intensity acquired by the same basalt sample demagnetized before shock (from Gattacceca et al., 2008, SRM0 in Table 1) (all shock experiments were performed under the same laser and ambient field conditions: laser flux of 1.8-1.9 $\mathrm{GW} \times \mathrm{cm}^{-2}$ ).

\section{Discussion}

These results demonstrate the two competing magnetic effects that occur when a shock wave passes through a rock: demagnetization of previous remanence and acquisition of shock remanence. It is noteworthy that the intensity of the SRM is independent of the initial state of the rock before the shock (figure 6). Similarly, the amount of shock demagnetization of the original NRM does not depend on the intensity of the ambient magnetic field at the time of impact (figure 4b). The two competing phenomena are thus independent even when they occur simultaneously. The exact same would be valid for TRM acquisition and the associated thermal demagnetization of the initial remanence.

Given that the pressure is not homogeneous within our shocked samples, it is not possible to interpret the curved shape of the demagnetization plots (figure 3c-d) as a proof that SRM and the remaining post-shock TRM have overlapping coercivity spectra, because we are measuring a bulk sample whose different regions have been shocked at different pressures. However, as shown in previous studies of demagnetization by hydrostatic pressure (e.g., Bezaeva et al., 2010), there is no equivalence between 
pressure demagnetization at a given pressure and a given alternating demagnetazation field, so that pressure demagnetization affects a large fraction of the coercivity spectrum with preferential demagnetization of low coercivity grains. It is therefore very probable that the curved shape of the demagnetization plots in figure 3c-d is due to overlapping coercivity spectra of SRM and post-shock TRM, i.e. incomplete TRM demagnetization and incomplete SRM acquisition over a large part of the coercivity spectrum.

As we know from this study (see §3) and from Gattacceca et al. (2008) that SRM acquisition in theses samples is almost homogeneous in the studied samples despite inhomogeneous pressure, it is reasonable to study the bulk behavior of the sample and compare the coercivity spectra of SRM and post-shock TRM (noted $\mathrm{TRM}_{2}$ in the following). We use as reference the coercivity spectrum of pre-shock TRM (noted TRM 1 in the following). Over every coercivity window defined by the AF demagnetization steps, we have computed the ratio $\Delta \mathrm{TRM}_{2} / \Delta \mathrm{TRM}_{1}$ to evaluate which fraction of the original TRM was erased by the shock, as well as the ratio $\Delta \mathrm{SRM} / \Delta \mathrm{TRM}_{1}$ to evaluate the efficiency of SRM acquisition with respect to TRM acquisition. This was done for a set of 13 samples that were shocked in the exact same conditions. Because there is only a small variation among the 13 samples, we provide the average values (figure 7). Shock demagnetization affects preferentially the low coercivity fraction of TRM as already discovered in a number of previous studies (Louzada et al., 2007; Bezaeva et al., 2007; Bezaeva et al., 2010), which is sometimes referred as shock "hardening" of the initial remanence (e.g. Brecher et al., 1979). Figure 7a shows that about 70\% of the TRM carried by grains with coercivities below $5 \mathrm{mT}$ is demagnetized by shock whereas grains with coercivity higher than $25 \mathrm{mT}$ are not affected. Figure $7 \mathrm{a}$ also shows that SRM efficiency with respect to TRM in the same field intensity decreases with coercivity. Indeed in the coercivity window below $3 \mathrm{mT}$ SRM is almost as intense as the original TRM whereas it is less than $10 \%$ above $10 \mathrm{mT}$. The bulk efficiency is $18 \%$ (s.d. $=5 \%$, $\mathrm{n}=20$ ), in agreement with the value of $14 \%$ obtained in Gattacceca et al. (2008). Another interesting aspect of figure $7 \mathrm{a}$ is that the two curves are significantly distinct. This difference is magnified in figure $7 \mathrm{~b}$, which displays the ratio $\Delta \mathrm{SRM} / \Delta \mathrm{TRM}_{2}$ as a function of coercivity. The fact that the curve in figure $7 \mathrm{~b}$ is not a horizontal line shows that although the two phenomena (shock magnetization and shock demagnetization) preferentially affect low coercivity grains, they are distinct phenomena that affect different grains with different intensities.

\section{Conclusion}

We have performed laser shock experiments on TRM-bearing basalt samples in a controlled magnetic field and studied the two competing phenomena that affect the magnetic remanence of these samples: shock demagnetization of the original remanence and shock magnetization in the ambient field at the time of impact.

As previously evidenced, SRM is strictly proportional to the ambient field at the time of impact and parallel to the ambient field. Moreover, we show that there is no directional or intensity heterogeneity of the SRM down to the scale of $\sim 0.2 \mathrm{~mm}^{3}$. We also show that the intensity of SRM is independent of the initial remanence state of the rock. As a consequence, when it can be recognized in a rock, SRM must be considered as a reliable record of the direction and intensity of the ambient magnetic field at the time of impact. This has potential implications for the paleomagnetic study of meteorites, and lunar rocks, and for the understanding of the magnetic signature (as studied through 
paleomagnetism and/or magnetic anomalies) of terrestrial, lunar and Martian impact craters.

Comparison of the coercivity spectra of SRM and shock demagnetized TRM show that the two phenomena (shock demagnetization and shock magnetization) preferentially affect low coercivity grains but not with the same intensity. As such, shock demagnetization cannot be considered as a limiting case of shock magnetization in zero field. The natural process of hypervelocity impact where a rock carrying a remanent magnetization is shocked in the presence of an ambient field can be studied as the simple superimposition of shock demagnetization and shock magnetization. For this there is now a variety of techniques that allow experimental study of both phenomena separately (Gilder et al., 2006; Louzada et al., 2007, Bezaeva et al., 2010; Gattacceca et al., 2008), or simultaneously as in this study. Simultaneous analysis of the two phenomena, although more experimentally demanding, permits reproducibility of both pressure and modification of rock magnetic and mechanical properties for both processes. 


\section{Figure captions}

figure 1 : Diagram of the experimental setup used in this work (modified from Gattacceca et al. (2008).

figure 2: Modeled peak pressure isocontours in a vertical section of the basalt sample upon laser shock with a flux of $1.80 \mathrm{GW} \cdot \mathrm{cm}^{-2}$ focused on a spot of $4.25 \mathrm{~mm}$ in diameter in water confined regime. Pressure values are in GPa.

figure 3: Orthogonal projection plots of stepwise demagnetization data of vertical downward pointing TRM bearing basalt samples a) shocked in zero ambient field b) before shock (same sample as in a) c) and d) shocked in horizontal eastward pointing ambient field of $100 \mu \mathrm{T}$ and $294 \mu \mathrm{T}$ respectively. Open and solid symbols are projections on vertical and horizontal planes, respectively.

figure 4: a) TRM lost upon shock (in \% versus the pre-shock TRM) as a function of the initial TRM intensity, b) TRM lost upon shock (in \% versus the pre-shock TRM) as a function of ambient field at the time of impact (ambient field oriented perpendicularly to the original TRM). s.d. are indicated by vertical bars and the number of samples in the mean is indicated.

figure 5: SQUID Microscope imaging of the magnetization in the shocked basalt. a) sketch of the sub-sampling procedure after laser shock and optical view of the slice (500 $\mu \mathrm{m} \times 10 \mathrm{~mm} \times 10 \mathrm{~mm}$ ) evidencing two millimetric olivine crystals on the right side. b) Vertical component of the SRM field measured $\sim 600 \mu \mathrm{m}$ above the sample (laser flux $2.0 \mathrm{GW} \cdot \mathrm{cm}^{-2}$, magnetic field $100 \mu \mathrm{T}$ ). c) and d) Horizontal components of the SRM field computed at the same height. e) and f) Magnetic moment distribution for the SRM and the anhysteretic remanent magnetization (acquired in a $40 \mathrm{mT} \mathrm{AF}$ and a bias field of $20 \mu \mathrm{T}$ ). In both cases, the magnetization is out-of-page. The spatial scale is the same for figures a to f. g) Average magnetization calculated along the topbottom direction for both maps (solid line = SRM; dashed line = ARM). Each curve is normalized by the corresponding overall average moment.

figure 6: SRM intensity acquired by basalt samples carrying a TRM (this study) vs SRM intensity acquired by the same samples demagnetized before shock (Gattacceca et al., 2008). In all cases, the shock experiment was performed with a laser flux of 1.8$1.9 \mathrm{GW} \cdot \mathrm{cm}^{-2}$. The ambient field varies from 5 to $294 \mu \mathrm{T}$. Each circle is for the same sample shocked in the same ambient field. Note the logarithmic scale on both axes.

figure 7: a) SRM efficiency vs TRM (blue boxes) and TRM demagnetization (red circles) as a function of coercivity. The AF value is the middle of the coercivity window of interest. SRM efficiency is defined as the ratio of SRM to preshock TRM (TRM $\left.{ }_{1}\right)$ acquired by grains with coercivities in the specified range. TRM demagnetization is defined as the ratio of TRM that was shock demagnetized (TRM $\left.{ }_{2}\right)$ to $\mathrm{TRM}_{1}$ for a given coercivity range. (b) Ratio of SRM acquired to TRM demagnetized as a function of coercivity (i.e. ratio of the two curves of figure $7 \mathrm{a}$ ). The AF value is the middle of the coercivity window of interest. Above $20 \mathrm{mT}$, this ratio is dominated by noise. 
Table 1 : Results of shock and thermoremanent magnetization experiments

$\mathrm{SRM}_{0}$ is the shock remanent magnetization acquired by initially demagnetized samples (from Gattacceca et al., 2008). $\mathrm{TRM}_{1}$ is a thermoremanent magnetization acquired by heating up to $300^{\circ} \mathrm{C}$. $\mathrm{SRM}_{1}$ is the shock remanent magnetization acquired by the samples initially carrying $\mathrm{TRM}_{1}$ ( $\dagger$ indicates that the shock was performed in null ambient field). The TRM demagnetization percentage indicates the decrease of $\mathrm{TRM}_{1}$ after shock. 


\section{References}

Acuña, M.H., J.E.P. Connerney, N.F. Ness, R.P. Lin, D. Mitchell, C.W. Carlson, J. McFadden, K.A. Anderson, H. Rème, C. Mazelle, D. Vignes, P. Wasilewski, P. Cloutier, 1999. Global Distribution of Crustal Magnetization Discovered by the Mars Global Surveyor MAG/ER Experiment. Science 284, 790-793, doi:10.1126/science.284.5415.790.

Bezaeva, N., Rochette, P., Gattacceca, J., Sadykov, R. A., Trukhin, V. I., 2007. Pressure demagnetization of the Martian crust: ground truth from SNC meteorites. Geophys. Res. Lett. 34, L23202, doi:10.1029/2007GL031501.

Bezaeva, N. S., Gattacceca, J., Rochette, P., Sadykov, R. A., Trukhin, V. I., 2010. Demagnetization of terrestrial and extraterrestrial rocks under hydrostatic pressure up to $1.2 \mathrm{GPa}$. Phys. Earth Planet. Interiors 179, 7-20.

Berthe, L., Bezaeva, N., Gattacceca, J., Boustie, M., Rochette, P., 2007. Mechanical characterization of basalt using shock wave induced by laser, Application to planetary hypervelocity impact effect, in Proceedings of the ICALEO 2007, Orlando (USA), p. 528-534.

Brecher A., Fuhrman M., 1979. The magnetic effects of brecciation and shock in meteorites: II. The ureilites and evidence for strong nebular magentic fields. The Moon and the Planets 20, 251-263.

Carporzen, L., Weiss, B.P., Ebel, D.S., Gattacceca, J., Shuster, D.L. (submitted) Evidence for a metallic core in the CV chondrite parent planetesimal. submitted to Science 12/2009.

Crawford, D.A., Schultz, P.H, 1988. Laboratory observations of impact-generated magnetic fields. Nature 336, 50-52.

Crawford, D.A., Schultz, P.H.,1999. Electromagnetic properties of impact-generated plasma, vapor and debris. Int. J. Impact Eng. 23, 169-180.

Dickinson, T.L., Wasilewski, P., 2000. Shock magnetism in fine particle iron. Meteor. Planet. Sci. 35, 65-74.

Fabbro, R., Fournier, J., Ballard, P., Devaux, D., Virmont, J., 1989. Physical study of laser-produced plasma in confined geometry. J. Appl. Phys. 68, 775-784.

Fisher, R., 1953. Dispersion on a sphere. Proc. R. Soc. London, Ser. A217, 295-305.

Fong, L. E., Holzer, J. R., McBride, K. K., Lima, E. A., Baudenbacher, F., Radparvar, M., 2005. High-resolution room-temperature sample scanning superconducting quantum interference device microscope configurable for geological and biomagnetic applications. Rev. Sci. Instrum. 76, 053703, doi:10.1063/1.1884025

Funaki, M., Syono Y., 2008. Acquisition of shock remanent magnetization for demagnetized samples in a weak magnetic field $(7 \mu \mathrm{T})$ by shock pressures 5-20 GPa without plasma-induced magnetization. Meteoritics Planetary Sci. 43, 1-13.

Gary, G., 2002. Comportement des métaux à grande vitesse de déformation : modélisationTechniques de l'ingénieur. Matériaux métalliques. MC1, M3036

Gattacceca, J., Boustie, M., Weiss, B. P., Rochette, P., Lima, E., Fong, L. E., Baudenbacher, F., 2006. Investigating impact demagnetization through laser impacts and SQUID microscopy. Geology 34, 333336.

Gattacceca, J., Lamali, A., Rochette, P., Boustie, M., Berthe L., 2007. The effects of explosive-driven shocks on the natural remanent magnetization and the magnetic properties of rocks. Phys. Earth Planet. Interiors 162, 85-98.

Gattacceca, J., Berthe, L., Boustie, M., Vadeboin, F., Rochette, P., de Resseguier, T., 2008. On the efficiency of shock magnetization processes. Phys. Earth Planet. Interiors 166, 1-10.

Gilder, S.A., Le Goff, M., Chevrin, J.-C., 2006. Static stress demagnetization of single and multidomain magnetite with implications to meteorite impacts. High Pressure Res. 26, 539-547.

Hood, L. L., Artemieva, N. A., 2008. Antipodal effects of lunar basin-forming impacts: Initial 3D simulations and comparisons with observations. Icarus, doi:10.1016/j.icarus.2007.08.023

Hood, L., Richmond, N. C., Pierazzo, E., Rochette, P., 2003. Distribution of crustal magnetic fields on Mars: shock effects of basin-forming impacts. Geophys. Res. Lett. 30, 10.1029/2002GL016657.

Kletetschka, G., Eonnerney, J.E.P., Ness, N.F., Acuña, M.H., 2004. Pressure effects on martian crustal magnetization near large impact basins. Meteor. Planet. Sci. 39, 1839-1848.

Lima, E.A. , Weiss B.P., 2009. Obtaining vector magnetic field maps from single-component measurements of geological samples. J. Geophys. Res. 114, B06102, doi: 10.1029/2008JB006006.

Louzada, K.L., Stewart, S.T., Weiss, B.P., 2007. Effect of shock on the magnetic properties of pyrrhotite, the Martian crust and meteorites. Geophys. Res. Lett. 34: L05204, doi: 10.1029/2006GL027685.

Louzada, K.L., Weiss, B.P., Maloof, A.C., Stewart, S.T., Swanson-Hysell, N.L., Soule, S.A., 2008. Paleomagnetism of Lonar impact crater, India. Earth Planet. Sci. Lett. 275, 308-319.

Louzada, K.L., Stewart, S.T., Weiss, B.P., Gattacceca, J., Bezaeva, N.S., 2009. Shock effects on pyrrhotite 
magnetism and implications for Martian crustal magnetization. Earth Planet. Sci. Lett. 290, 90-101.

Nagata, T., 1971. Introductory notes on shock remanent magnetization and shock demagnetization of igneous rocks. Pure Applied Geophys. 89, 159-177.

Nagata, T., Funaki, M., Dunn, J. R., 1983. Shock remanent magnetization of meteorites. Mem. National Institute Polar Res. 30, 435-446.

Néel, L. 1949. Théorie du trainage magnétique des ferromagnétiques en grains fins avec applications aux terres cuites. Ann. Géophys. 5, 99-136.

Pohl, J., Bleil, U., Hornemann, U., 1975. Shock magnetization and demagnetization of basalt by transient stress up to 10 kbar. J. Geophysics, 41, 23-41.

Pohl, J., Eckstaller, A., 1981. The Effect of Shock on Remanence in Multi-Domain Iron Grains and Implications for Palaeointensity Measurements. Lunar Planet. Sci. XII, 851-853.

Rochette, P., Fillion, G., Ballou, R., Brunet, F., Oulladiaf, B., Hood, L., 2003. High pressure magnetic transition in pyrrhotite and impact demagnetization on Mars. Geophys. Res. Lett. 30, 1683, doi:10.1029/2003GL017359.

Shahnas, H., Arkani-Hamed, J., 2007. Viscous and impact demagnetization of Martian crust. J. Geophys. Res. 112, doi:10.1029/2005JE002424.

Soloviev, S.P., Sweeney, J. J., 2005. Generation of electric and magnetic field during detonation of high explosive charges in boreholes. J. Geophys. Res. 110, B01312, doi:10.1029/2004JB003223.

Weiss, B. P., Lima, E. A., Fong, L. E., Baudenbacher, F. J., 2007. Paleomagnetic analysis using SQUID microscopy, J. Geophys. Res. 112, B09105, doi:10.1029/2007JB004940.

Yu, Y., Doh, S.-J., Kim, W., Min, K., 2009. Ancient stable magnetism of the Richardton H5 chondrite. Phys. Earth Planet. Interiors 177, 12-18. 


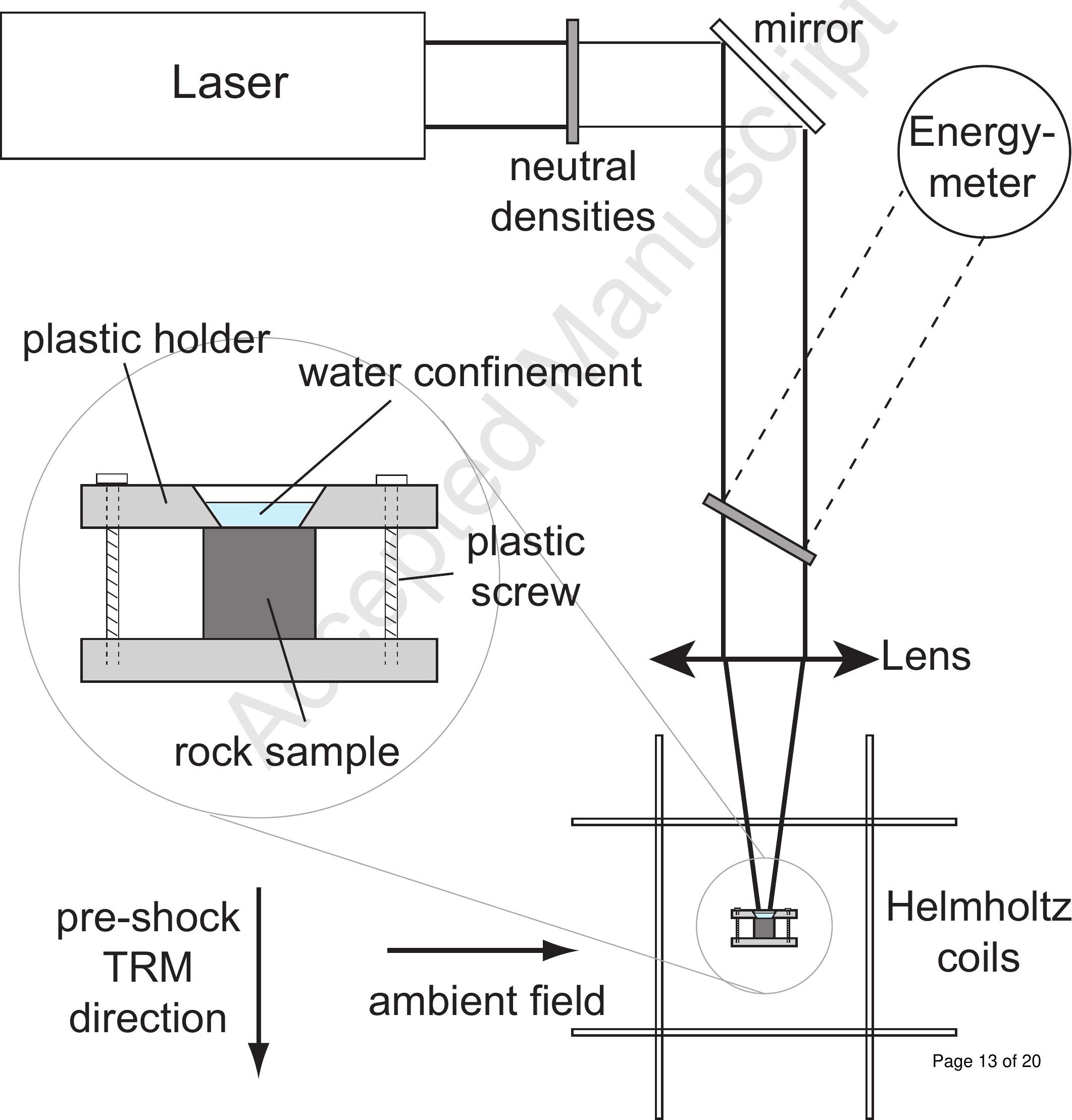




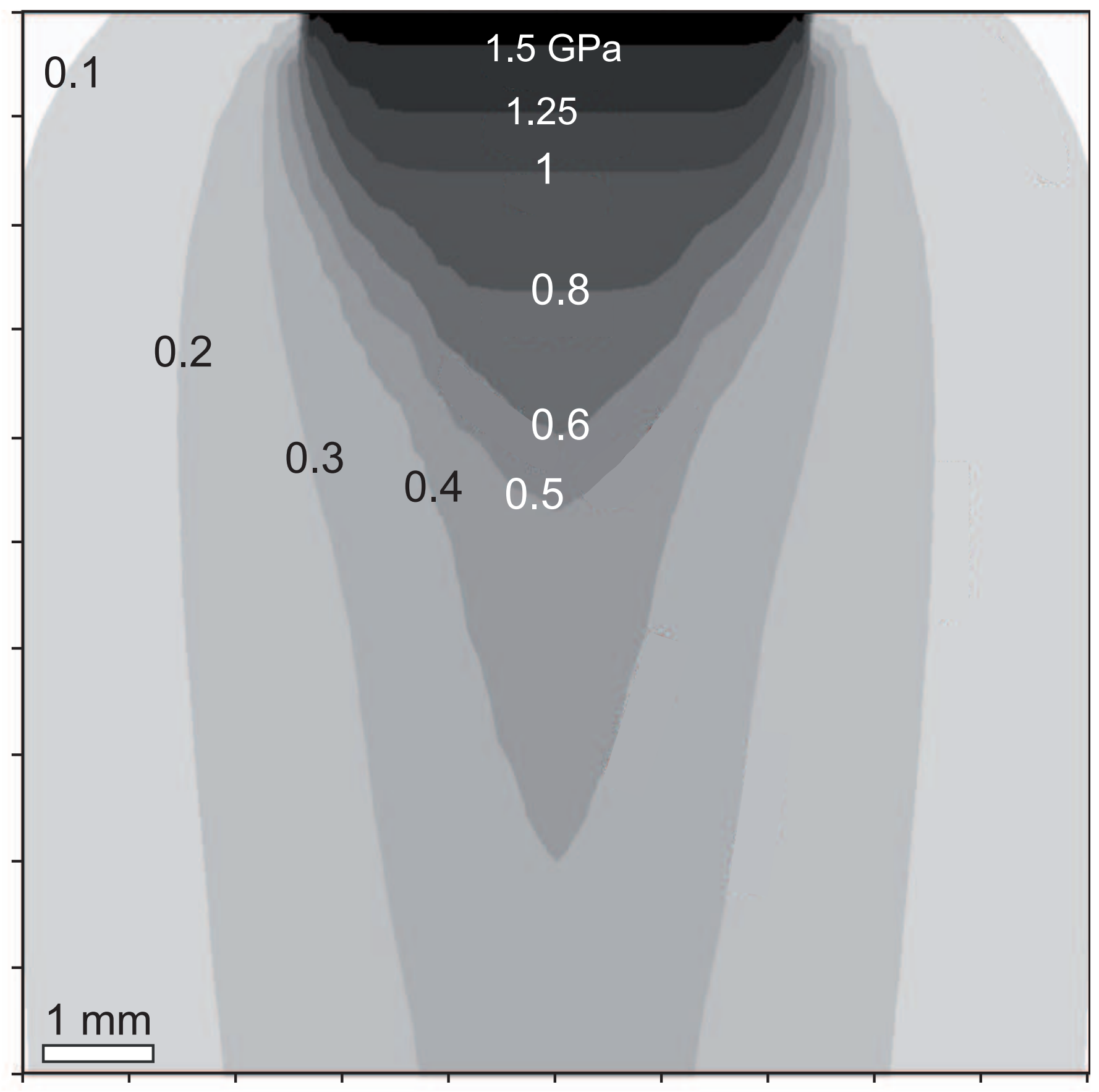



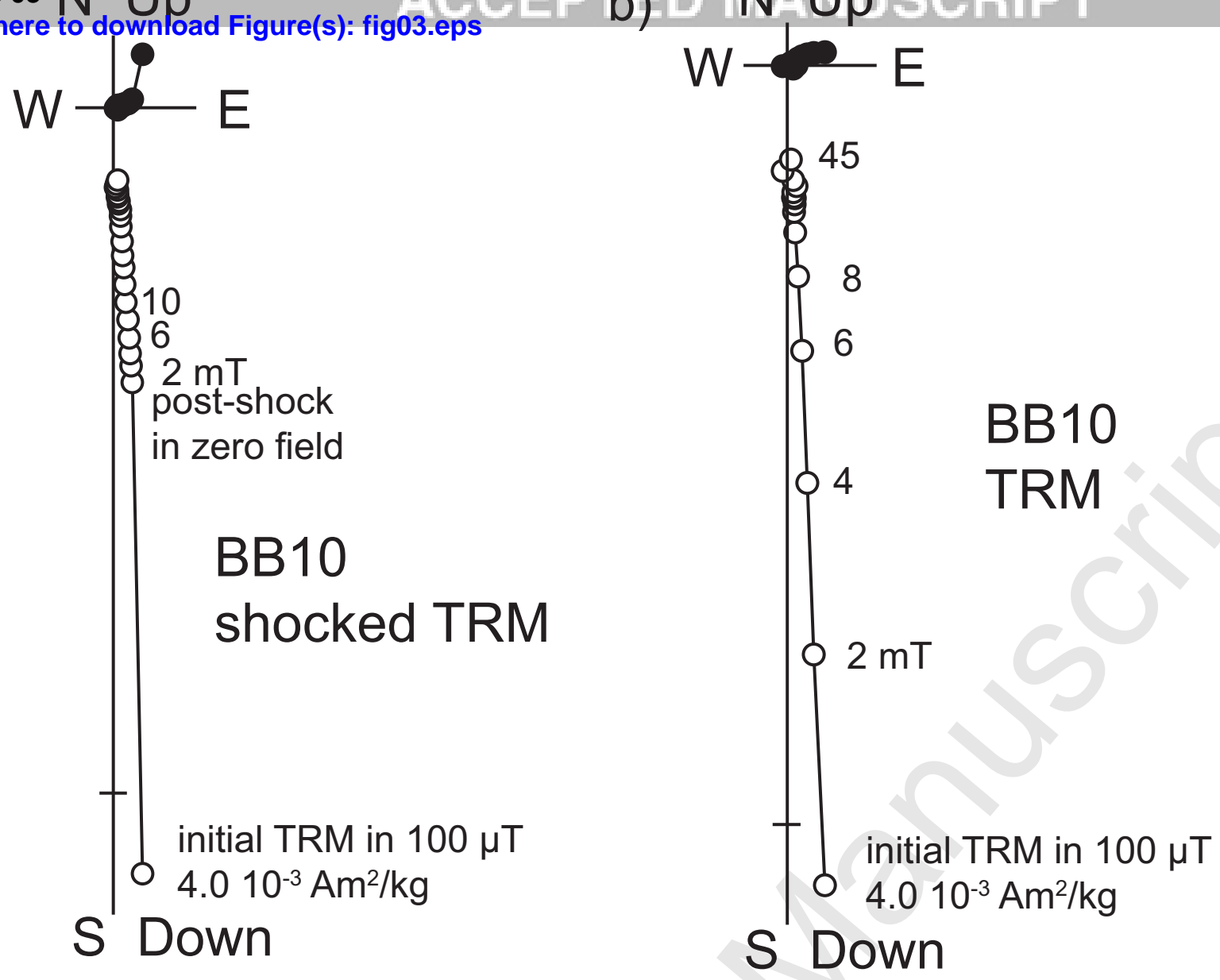

c)

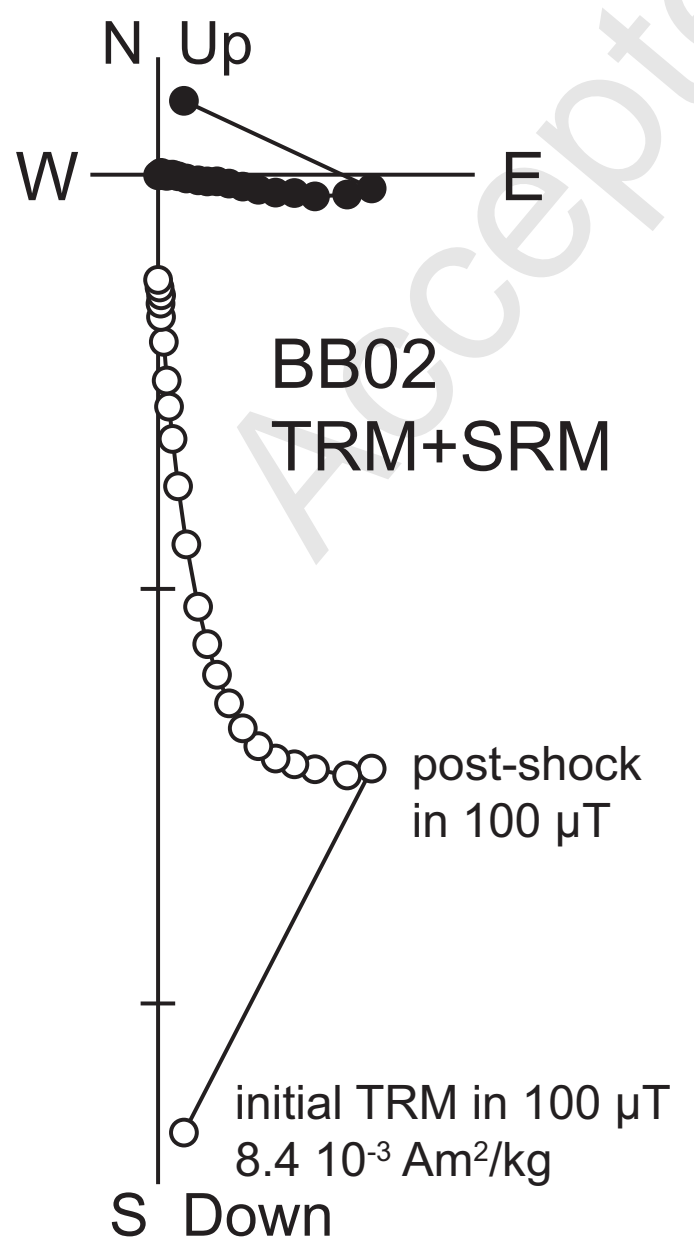

d) $\quad \mathrm{N} \cup p$

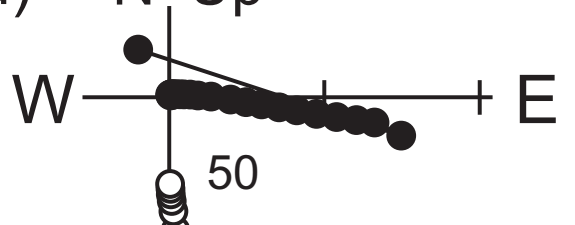

8

BB14 $T R M+S R M$ 8. $42 \mathrm{mT}$

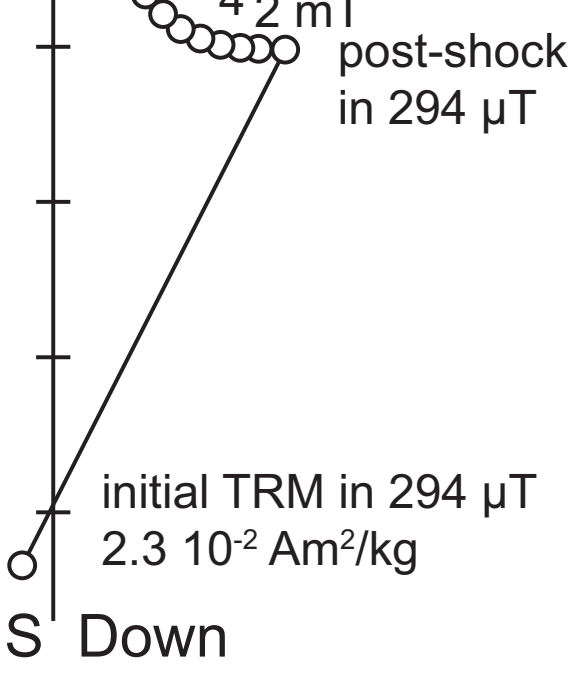

Page 15 of 20 


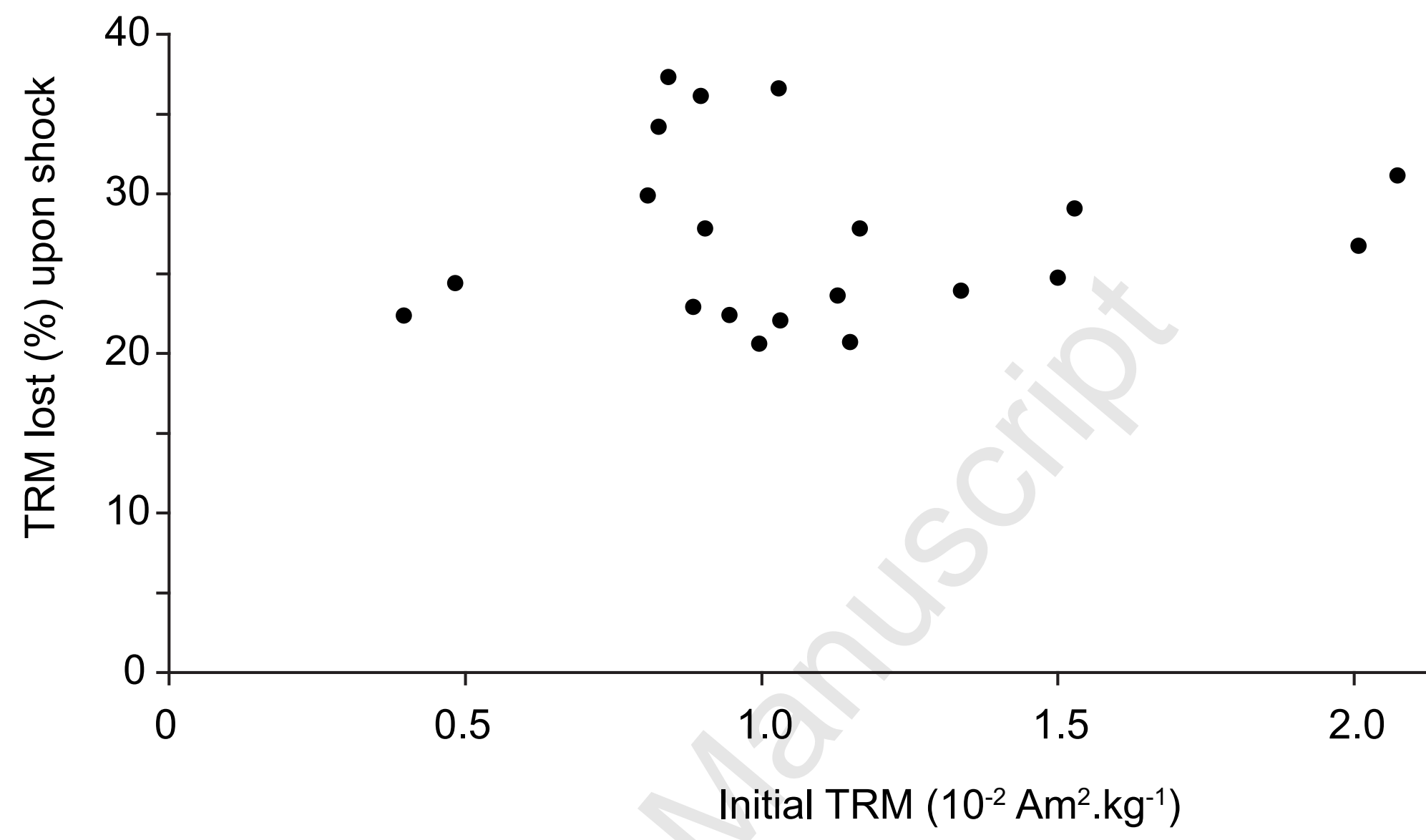

b)

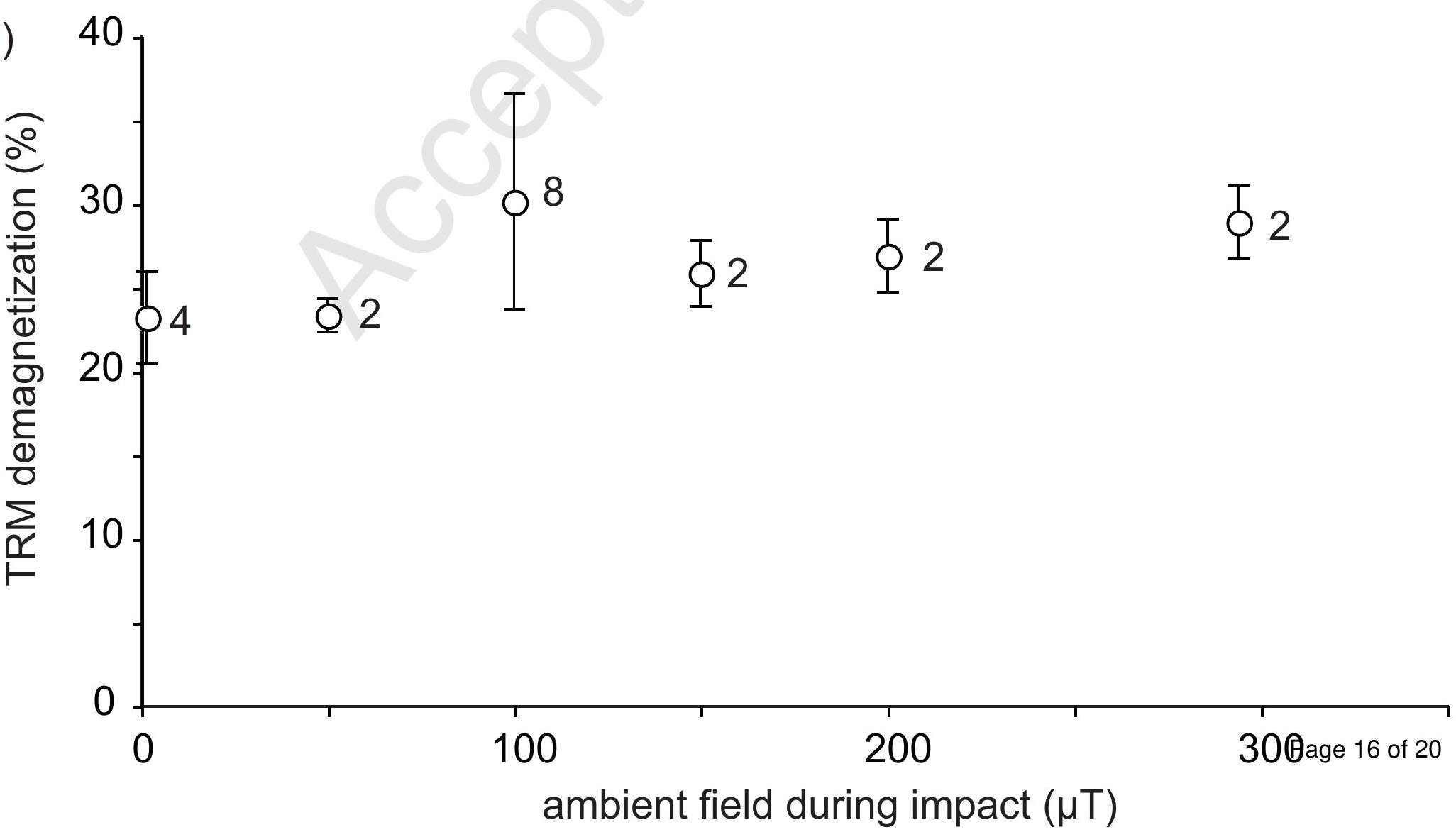


a)

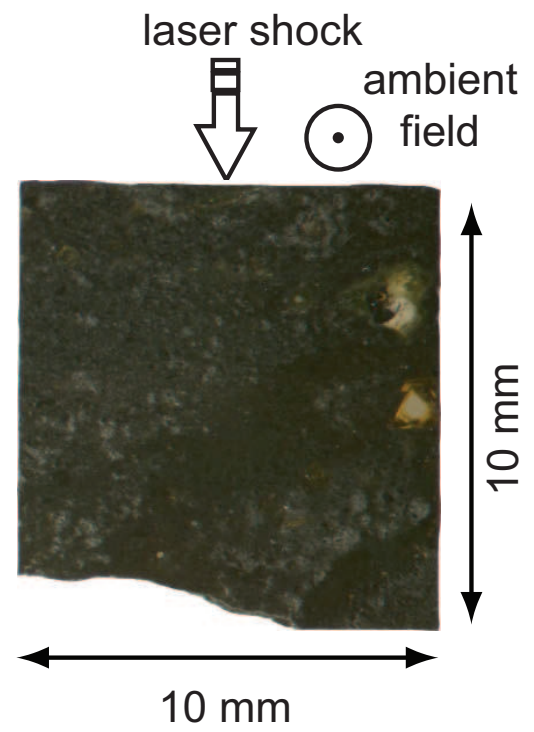

c)

X component b)

200

100

$0 \mathrm{nT}$

$-100$

- Z component

$-200$

d)

100

50

$0 \mathrm{nT}$

$-50$

$-100$

$-150$

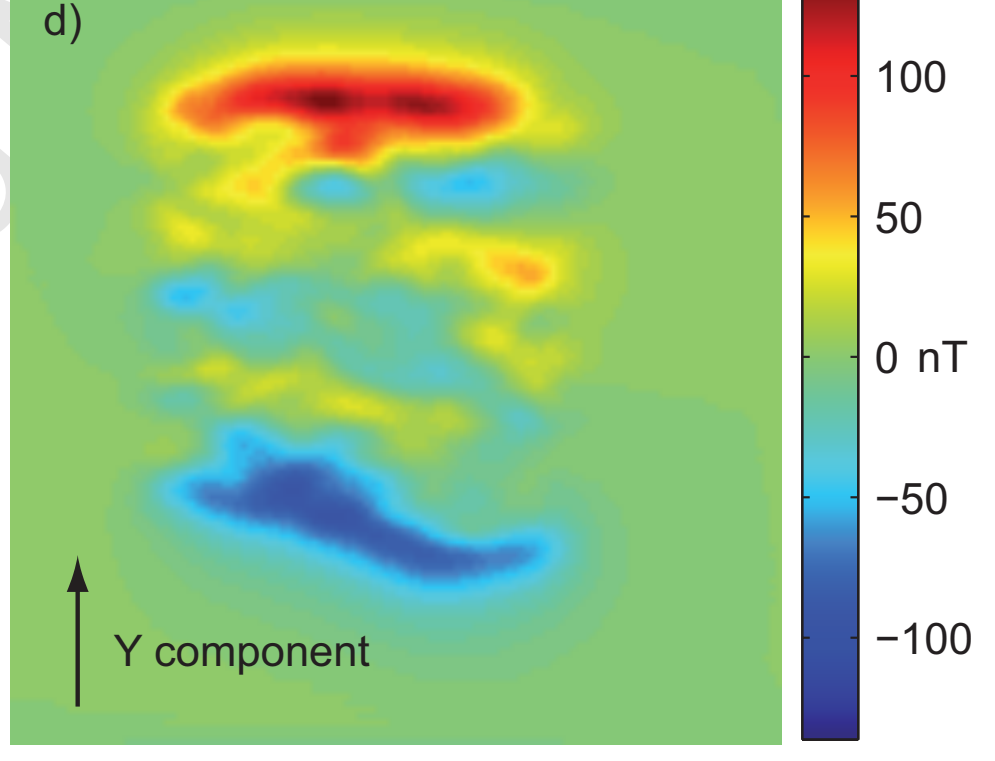

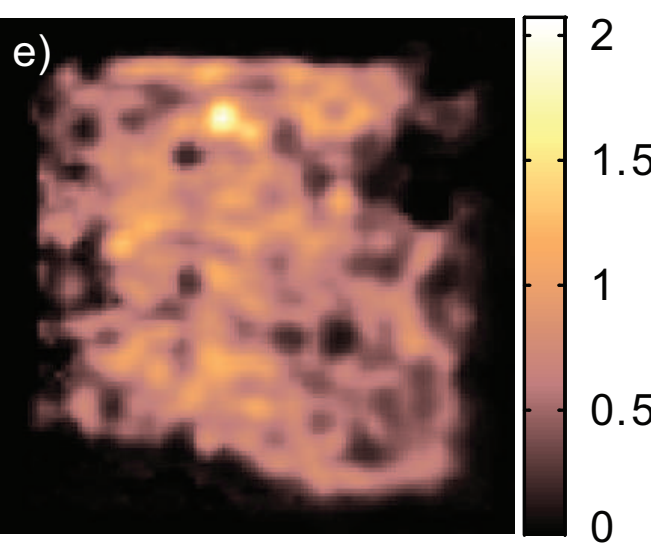

magnetization

$10^{-10} \mathrm{Am}^{2}$

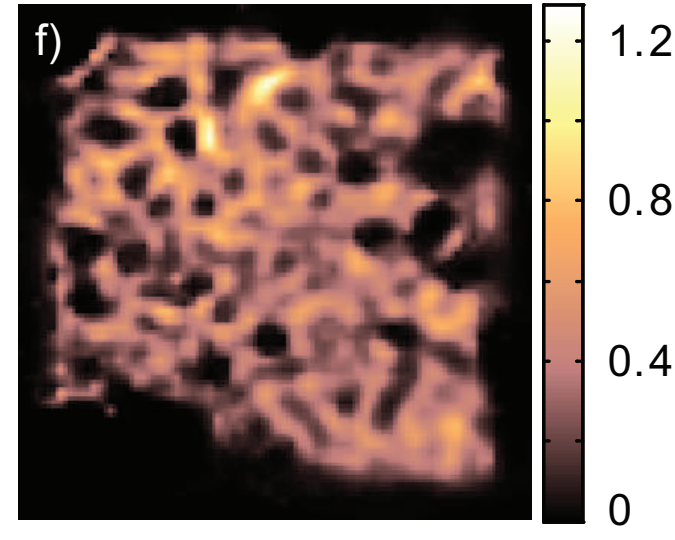

magnetization $10^{-10} \mathrm{Am}^{2}$



horizontal axis

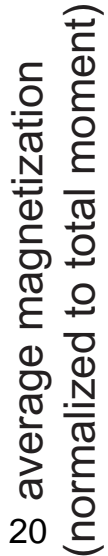
Page 17 of $20 \subseteq$ 


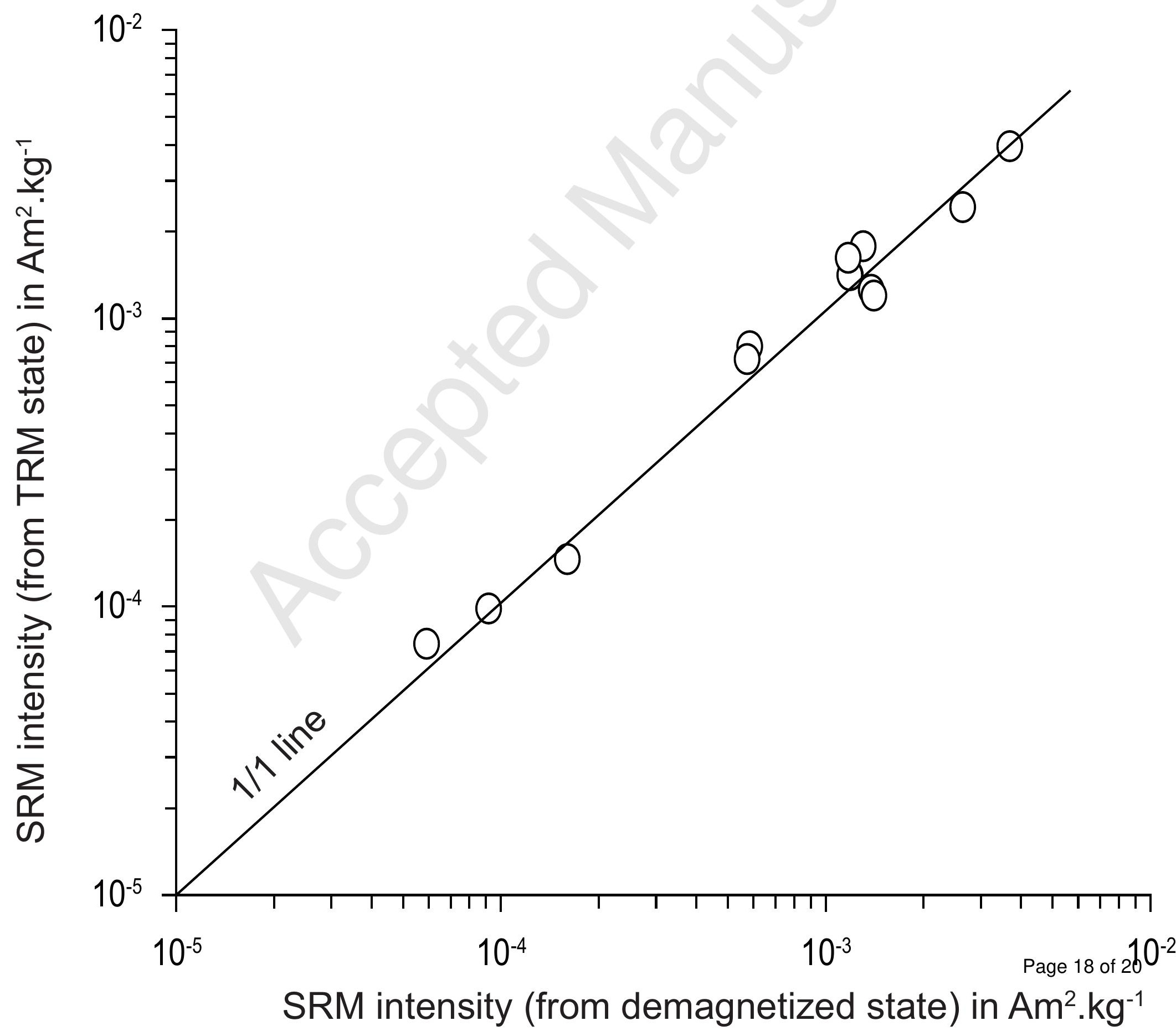



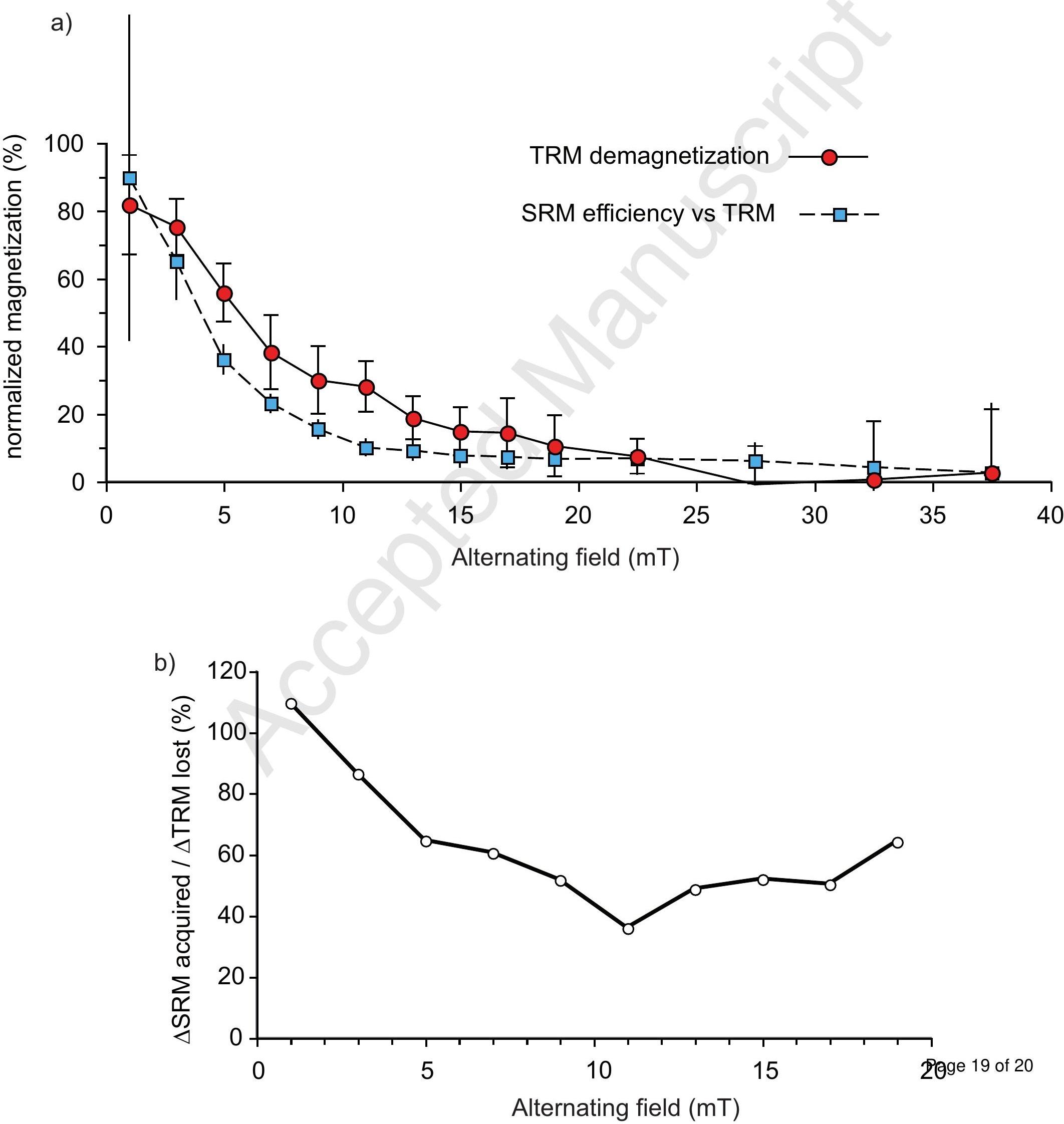


\begin{tabular}{|c|c|c|c|c|c|c|c|c|}
\hline sample & $\begin{array}{l}\text { Magnetizing } \\
\text { field } \mathrm{SRM}_{0} \\
\qquad(\mu \mathrm{T})\end{array}$ & $\begin{array}{c}\text { laser } \\
\text { power } \\
\text { SRM }_{0} \\
\text { GW.cm-2 }\end{array}$ & $\left(\mathrm{Am}^{2} \cdot \mathrm{kg}^{-1}\right)$ & $\begin{array}{l}\text { Magnetizing } \\
\text { field } \mathrm{TRM}_{1} \\
\text { and } \mathrm{SRM}_{1} \\
(\mu \mathrm{T})\end{array}$ & $\begin{array}{c}\mathrm{TRM}_{1} \\
\left(\mathrm{Am}^{2} \cdot \mathrm{kg}^{-1}\right)\end{array}$ & $\begin{array}{c}\text { laser } \\
\text { power } \\
\text { SRM }_{1} \\
(\text { GW.cm-2) }\end{array}$ & $\left(\mathrm{Am}^{2} \cdot \mathrm{kg}^{-1}\right)$ & $\begin{array}{c}\text { TRM } \\
\text { demag. } \\
(\%)\end{array}$ \\
\hline BB22 & 100 & 1,83 & $1,16 \mathrm{E}-03$ & $100^{+}$ & $9,04 \mathrm{E}-03$ & 1,94 & $1,80 \mathrm{E}-04$ & 28 \\
\hline BB40 & 100 & 1,65 & $1,15 \mathrm{E}-03$ & $100^{+}$ & 1,03E-02 & 1,84 & $3,49 \mathrm{E}-04$ & 22 \\
\hline BB41 & 100 & 1,79 & $1,06 \mathrm{E}-03$ & $100^{+}$ & $9,95 \mathrm{E}-03$ & 1,84 & 3,87E-04 & 21 \\
\hline BB46 & 0 & 1,75 & $1,72 \mathrm{E}-05$ & $100^{+}$ & $9,46 \mathrm{E}-03$ & 1,82 & $5,44 \mathrm{E}-05$ & 22 \\
\hline BB2 & 100 & 1,59 & 1,18E-03 & 100 & $7,95 \mathrm{E}-03$ & 1,9 & $1,43 \mathrm{E}-03$ & 37 \\
\hline BB5 & 100 & 1,8 & $1,29 \mathrm{E}-03$ & 100 & 8,93E-03 & 1,87 & $1,80 \mathrm{E}-03$ & 34 \\
\hline BB7 & 100 & 1,59 & $1,18 \mathrm{E}-03$ & 100 & 8,92E-03 & 1,8 & $1,43 \mathrm{E}-03$ & 36 \\
\hline BB18 & 1 & 1,6 & $6,70 \mathrm{E}-05$ & 100 & $7,86 \mathrm{E}-03$ & 1,91 & $1,82 \mathrm{E}-03$ & 30 \\
\hline BB19 & 0,5 & 1,87 & $4,49 \mathrm{E}-05$ & 150 & $1,22 \mathrm{E}-02$ & 1,72 & 2,91E-03 & 28 \\
\hline BB26 & 600 & 2,03 & $7,47 \mathrm{E}-03$ & 294 & 2,18E-02 & 1,79 & $4,00 \mathrm{E}-03$ & 31 \\
\hline BB30 & 600 & 2,09 & $6,94 \mathrm{E}-03$ & 50 & $4,98 \mathrm{E}-03$ & 1,79 & 8,11E-04 & 24 \\
\hline BB31 & 0 & 1,77 & 5,12E-05 & 100 & $1,11 \mathrm{E}-02$ & 2,03 & $1,03 \mathrm{E}-03$ & 24 \\
\hline BB33 & 1 & 2,01 & $9,43 \mathrm{E}-05$ & 294 & 2,07E-02 & 1,79 & $3,27 \mathrm{E}-03$ & 27 \\
\hline BB34 & 50 & 1,94 & 5,69E-04 & 50 & 4,07E-03 & 1,82 & 7,29E-04 & 22 \\
\hline BB43 & 100 & 1,84 & $1,16 \mathrm{E}-03$ & 100 & $1,08 \mathrm{E}-02$ & 1,88 & $1,64 \mathrm{E}-03$ & 37 \\
\hline BB45 & 200 & 2 & $2,63 \mathrm{E}-03$ & 200 & 1,59E-02 & 1,84 & $2,46 \mathrm{E}-03$ & 25 \\
\hline BB48 & 100 & 1,98 & $1,37 \mathrm{E}-03$ & 100 & $9,06 \mathrm{E}-03$ & 1,88 & 1,27E-03 & 23 \\
\hline BB49 & 100 & 1,95 & $1,40 \mathrm{E}-03$ & 100 & $1,14 \mathrm{E}-02$ & 1,81 & $1,21 \mathrm{E}-03$ & 21 \\
\hline BB63 & 2500 & 1,8 & $2,74 \mathrm{E}-02$ & 150 & 1,39E-02 & 1,82 & 2,85E-03 & 24 \\
\hline BB65 & 0,5 & 2,31 & $8,11 \mathrm{E}-05$ & 200 & $1,62 \mathrm{E}-02$ & 1,84 & $3,90 \mathrm{E}-03$ & 29 \\
\hline BB10 & 100 & 1,59 & 1,37E-03 & $100^{+}$ & 4,03E-03 & 4,08 & 5,57E-05 & 64 \\
\hline BB44 & 1000 & 1,96 & $1,06 \mathrm{E}-02$ & 294 & 7,51E-03 & 3,45 & $2,40 \mathrm{E}-04$ & 56 \\
\hline BB14 & 2000 & 1,08 & $2,27 \mathrm{E}-02$ & 294 & $2,27 \mathrm{E}-02$ & 4,74 & $6,05 \mathrm{E}-03$ & 52 \\
\hline
\end{tabular}

